\title{
Üç port ve konvansiyonel ekstraperitoneal laparoskopik radikal prostastatektomi uygulanan hastalarda erektil fonksiyonun karșılaștırılması
}

\author{
Comparison of erectile function in patients undergoing extraperitoneal \\ laparoscopic radical prostastatectomy by three port and conventional \\ method
}

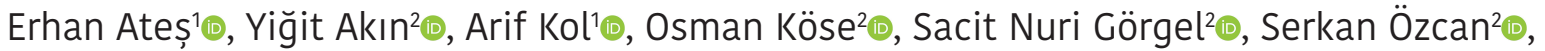 \\ Yüksel Yılmazº
}

\section{öz}

AMAC̦: Prostat kanseri nedeniyle 3-port ve konvansiyonel yöntemle ekstraperitoneal laparaskopik radikal prostatektomi (eLRP) uygulanan hastaların postoperatif erken dönem erektil fonksiyonlarını karşılaştırmayı amaçladık.

GEREC ve YÖNTEM: Eylül 2016 ve Ekim 2018 arasında prostat kanseri nedeni ile eLRP yapılan hastaların verileri retrospektif olarak değerlendirildi. Tüm hastalar 3 port ile eLRP yapilan ve konvansiyonel eLRP yapılanlar olarak iki gruba ayrıldı. Hastaların erektil fonksiyonlarını değerlendirmek için preoperatif ve postoperatif 6 . ayda uluslararası erektil fonksiyon indeksi-5 (IIEF-5) formu kullanıld. IIEF-5 skoru >21 olan hastalar potent, IIEF-5 skoru $<11$ ise ciddi erektil disfonksiyon (ED) olarak kabul edildi. Preoperatif dönemde potent olan hastalardan 3-port eLRP ve konvansiyonel eLRP yapılanların postoperatif 6 . aydaki IIEF-5 skorları karşılaştırıldı.

BULGULAR: Toplamda eLRP uygulanan 92 hasta çalışmaya dahil edildi. Bunlardan 23'ü 3-port eLRP, 69'u konvansiyonel eLRP hastası idi. Ortalama hasta yaşı $63,4 \pm 6,10$ yıl, tanıdaki ortalama prostat spesifik antijen (PSA) değeri $10,7 \pm 8,55 \mathrm{ng} / \mathrm{dL}$ olarak bulundu. Gruplar arasında yaş, PSA, preoperatif ve postoperatif Gleason skoru, klinik ve patolojik evre, nörovasküler demet korunma oranı, cerrahi sınır pozitiflik oranı ve postoperatif kontinans ve 6 . ayda erektil fonksiyon açısından 3-port ve konvansiyonel teknik açısından istatistiksel olarak anlamlı farklılık saptanmadı.

SONUC:: Onkolojik, cerrahi ve erken dönem fonksiyonel sonuçlar bakımından konvansiyonel yöntemle benzer olan 3-port eLRP, daha iyi kozmetik sonuçlarla erektil fonksiyonları da koruyarak prostat kanserinin tedavisinde minimal invaziv cerrahi yaklaşım olarak güvenle tercih edilebilir.

Anahtar Kelimeler: Üç port laparaskopi, radikal prostatektomi, erektil disfonksiyon, prostat kanseri

${ }^{7}$ Aydın Adnan Menderes Üniversitesi Tıp Fakültesi Üroloji Anabilim Dalı, Aydın, Türkiye 2izmir Katip Çelebi Üniversitesi Tıp Fakültesi Üroloji Anabilim Dalı, İmir, Türkiye

\section{Yazıșma Adresi/ Correspondence:}

Dr. Öğr. Üyesi Erhan Ateș

Aydın Adnan Menderes Üniversitesi Tıp Fakültesi, Üroloji Anabilim Dalı,

09010 Aydın, Türkiye

Tel. $\quad+905065323143$

E-mail: drerhanates@yahoo.com

Geliş/ Received: $\quad 25.02 .2019$

Kabul/ Accepted: 03.04 .2019

\section{ABSTRACT}

OBJECTIVE: We aimed to compare the early postoperative erectile functions of patients who underwent extraperitoneal laparascopic radical prostatectomy (eLRP) with 3-port and conventional methods for prostate cancer.

MATERIAL and METHODS: We reviewed the medical records of the patients who underwent radical prostatectomy between September 2016 and October 2018 retrospectively. The patients were divided into two groups as 3-ports eLRP and conventional eLRP. International erectile function index-5 (IIEF-5) form was used preoperatively and postoperatively at the 6th month to evaluate the erectile function of the patients. Patients with IIEF-5 score $>21$ were considered as potent, and IIEF-5<11 was considered as severe erectile dysfunction (ED). IIEF-5 scores of preoperatively potent patients who underwent 3-port eLRP and conventional eLRP were compared at postoperative 6th month.

RESULTS: In total, 92 patients who underwent eLRP were included in the study. Of these, 23 were 3-port eLRP, 69 were conventional eLRP patients. Mean age was $63.4 \pm 6.10$ years, mean prostate specific antigen (PSA) was $10.7 \pm 8.55 \mathrm{ng} / \mathrm{dl}$. There were no statistically difference between compared groups in terms of age, PSA, preoperative and postoperative Gleason score, clinical and pathological stage, neurovascular bundle protection, positive surgical margin, postoperative continence status and postoperative erectile function 6th month.

CONCLUSION: The 3-port eLRP, which is similar to the conventional method in terms of oncologic, surgical and early functional results, can be preferred as a minimally invasive surgical approach in the treatment of prostate cancer by maintaining erectile functions with better cosmetic results.

Keywords: Three port laparascopy, radical prostatectomy, erectile dysfunction, prostate cancer

\section{Gíniș}

Günümüzde, klinik olarak organa sınırlı prostat kanserinin (PCa) cerrahi tedavi seçeneği radikal prostatektomidir (RP). [1] Radikal prostatektomide hedef hastalığın onkolojik eradikasyonunu sağlarken, yaşam kalitesinin devamlılığı için önemli olan kontinans ve erektil fonksiyonları korumaktır. ${ }^{[2]}$

Onlarca yıl açık cerrahi teknik ile RP lokalize PCa'da standart cerrahi tedavi yöntemi olarak kabul edildi. ${ }^{[3]} 1991$ 
yılında ilk laparoskopik RP (LRP) Schussler ve ark. tarafindan tarif edilmesinden bu yana minimal invaziv cerrahi olarak yaygın şekilde uygulanmaktadır. ${ }^{[4,5]}$ Açık RP ile benzer onkolojik sonuçları bulunan LRP'nin avantajları, daha az postoperatif ağrı, daha kısa hospitalizasyon süresi, günlük aktiviteye hızlı dönüş, azalmış kan kaybı ve potensin daha erken normale gelmesi sayılabilir. ${ }^{[6]}$

Günümüzde gelişen teknoloji cerrahi aletlere de yansımaktadır. Baş döndürücü gelişmeler ile yakın zamanda robot yardımlı RP (RYRP) literatürde hızla yerini almıştır. [7] Genel hatları ile RYRP'nin gelişmesi ile LRP geri plana atılmaktadır. Her ne kadar uygulama, operasyon ve operasyon sonrası sonuçları ile cerrahi üstünlük avantajı RYRP'nin gibi görünsede ülkemiz ve dünya genelinde işlem ve cihaz bakım maliyeti göz önüne alındığında RYRP yaygınlaşması beklendiği kadar olmamışır. Güncel uluslararası kongrelerde de robotik cerrahi imkanı bulunmayan kliniklerde PCa’nın minimal invaziv cerrahi tedavi seçeneği olarak LRP'nin sunulması LRP'nin önemini halen koruduğunu göstermektedir.

Beş ya da altı trokar kullanılarak gerçekleştirilen konvansiyonel LRP'de ${ }^{[8]}$ trokar girişlerine bağlı gelişen epigastrik damar yaralanması, viseral organ hasarı, yara enfeksiyonu ve port yeri hernisi gibi komplikasyonlar insizyon ve port sayısını azaltma yönünde bir eğilime neden olmuştur. Hatta tek insizyonlu uygulamalar için LESS (laparoendoscopic single-site surgery) terimi kabul edilmiştir. ${ }^{[9]}$ Literatürde iki ve dört trokar kullanılarak yapılan LRP'ler ile ilgili deneyimler bildirilmekle birlikte ${ }^{[10,11]}$ sadece üç trokar kullanılan eLRP tanımlanmamıştır.

Çalışmamızda hem 3-port uygulanan eLRP serimizi sunmayı, hem de 3-port eLRP ve konvansiyonel 5-port eLRP uygulanan hastaların postoperatif erken dönem erektil fonksiyonlarını karşılaştırmayı amaçladık.

\section{GEREÇ VE YÖNTEM}

Geriye dönük hastane bilgi işlem sistemi ve hasta dosyaları incelenerek Eylül 2016 ve Ekim 2018 arasında PCa nedeni ile eLRP yapılan hastalar çalışmaya dahil edildi. Hastaların ıslak imzalı onam formları operasyon öncesinde alındı. Tüm hastalara tek bir cerrah tarafindan (Y. A.) modifiye Heilbronn tekniği ${ }^{[12]}$ ile eLRP uyguland. Hastaların preoperatif klinik evre, tümör lokalizasyonu, ve tümör yüküne göre sinir koruyucu cerrahi planlaması yapıldı ve uygulandı. Çalışmadan dışlanma kriteri hastaların düzenli poliklinik takibine gelmemesi ve verilerin tam olmaması, önceden erektil disfonksiyona (ED) sahip olmak olarak belirlendi.
Operasyon öncesindeki yaş, prostat spesifik antijen (PSA), biyopsi verileri, Gleason skoru, komorbidite, geçirilmiş operasyon, klinik evre gibi verilerin yanı sıra intraoperatif ve postoperatif takiplerde elde edilen veriler Microsoft Excel veri sayfalarına kaydedildi. Tüm hastaların preoperatif kontinans durumları sorgulandı ve erektil fonksiyonlarını değerlendirmek amaçlı uluslararası erektil fonksiyon indeksi-5 (IIEF-5) formu dolduruldu. IIEF-5 skoru $>21$ olan hastalar potent, IIEF-5 skoru <21 olanlar şiddetleri değişmekle birlikte impotent olarak kabul edildi. IIEF-5 formu preoperatif ve postoperatif 6 . ayda aynı doktor tarafindan değerlendirildi. Tüm hastalar 3 trokar ile eLRP yapilan ve konvansiyonel 5 ve/veya 6 trokar ile eLRP yapılanlar olarak iki gruba ayrıldı ve elde edilen veriler analiz edildi.

\section{Cerrahi Teknik}

3-port ekstraperitoneal Laparoskopik Radikal Prostatektomi

Hastaların tümü supin ve $30^{\circ}$ modifiye Trendelenburg pozisyonunda öncelikle göbek altına gülen yüz kesi yapıldıktan sonra Balon trokar (Braun, Almanya) kullanılarak (Şekil 1a) Retzius'ta yeterli alan oluşturuldu, sağa ve sola göbek mesafesinden 4 parmak uzaklığa 10 mm'lik çalışma trokarları yerleştirildi (Şekil 1b). Pnömoretroperitoneum oluşturulduktan sonra ilk olarak bilateral obturator lenf nodu diseksiyonu yapild. Daha sonra bilateral endopelvik fasyalar kesildi ve derin dorsal veni bağlamak için $2 / 0$ V-Lok sütürü kullanıldı (Şekil 1c). Ardından derin dorsal ven dikkatlice kesildi, üretra diseke edildi ve üretral güdük olabildiğince uzun bırakılarak üretra transekte edildi (Şekil 1d). Daha sonra üretral Foley sonda hafifçe traksiyona alındı ve mesane boynu koruyucu teknik kullanılarak mesane boynu disseke edildi. Mesane boynu kesildikten sonra bilateral vaz deferensler ve seminal veziküller sırasıyla disseke ve transekte edildi. Tümör nörovasküler demete invaze değil ise interfasyal sinir koruyucu teknik kullanılarak nörovasküler demet korundu (Şekil 1e). İki adet 3/0 V-lok dikiş bir araya getirildi ve Van Velthoven tekniği ile üretra-vezikal anastomoz gerçekleştirildi (Şekil 1f). Daha sonra drenaj kateteri yerleştirildi ve operasyona son verildi (Şekil 2a). Postoperatif 7. gün sistografi eşliğinde sonda alındı (Şekil 2b).

\section{Konvansiyonel eLRP}

Konvansiyonel laparoskopide ise yukarıda anlatılanlara ek olarak optik görüntüleme altında sağ ve sol laterallere 5 mm'lik birer çalışma trokarı konuldu. İhtiyaça göre trokar sayısı artırıldı. 3-port eLRP'de anlatılan cerrahi prosedür birebir aynı olarak uygulandı. 

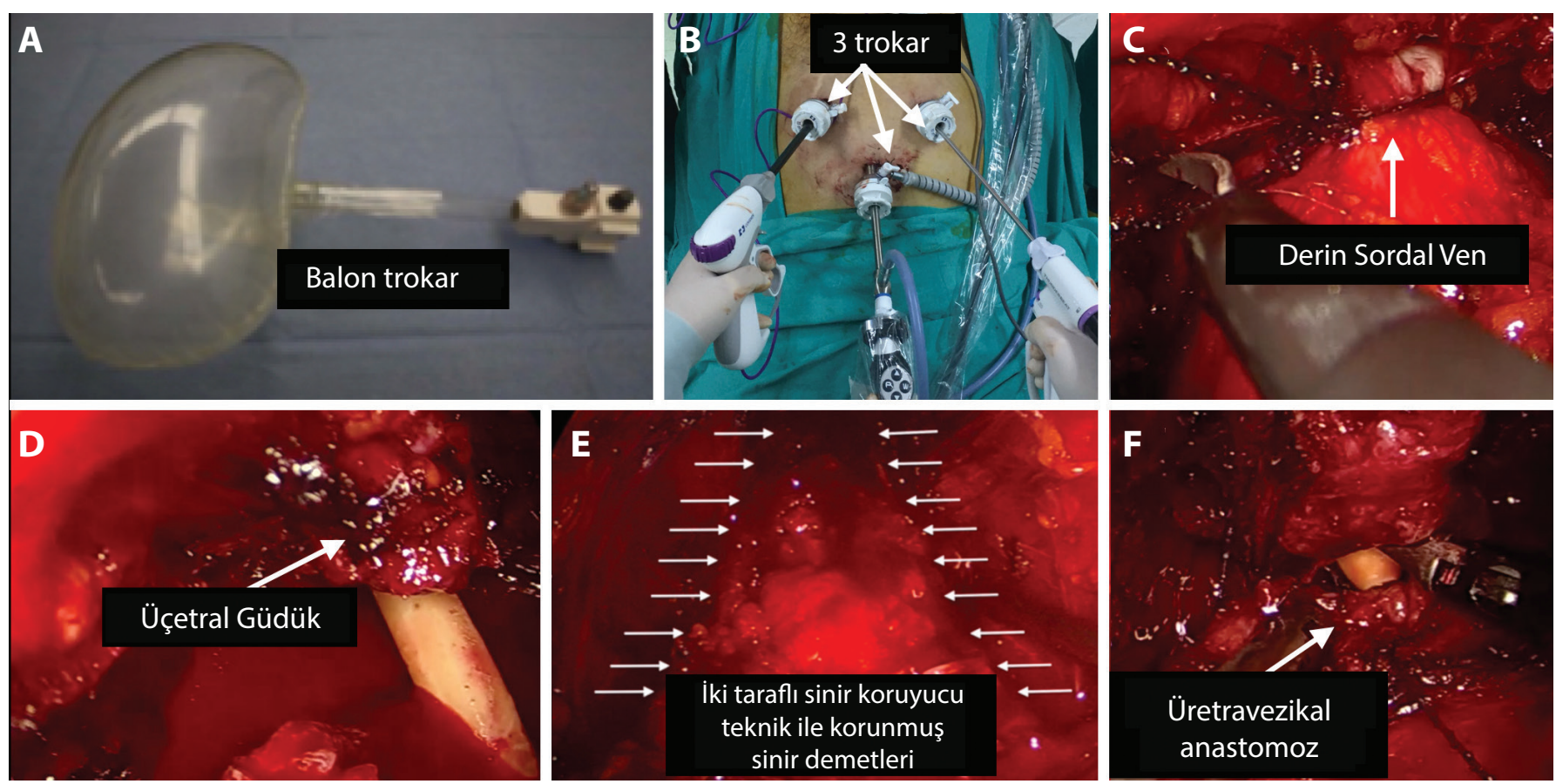

Şekil 1. Üç trokar ekstraperitoneal laparoskopik radikal prostatektomide cerrahi tekniğin tarifi: Balon trokar ile retzius boşluğu oluşturulması (a); Cerrahi prosedür sırasında kullanılan trokarların yerleşimi (b); Derin dorsal ven pleksusunun bağlanması (c); Üretranın kesilmesi ve uzun üretral güdük bırakılması (d); iki taraflı sinir koruyucu yapılmış vakadan görüntü (e); Üretrovezikal anastomoz (Van Velthoven tekniğine uygun) (f).

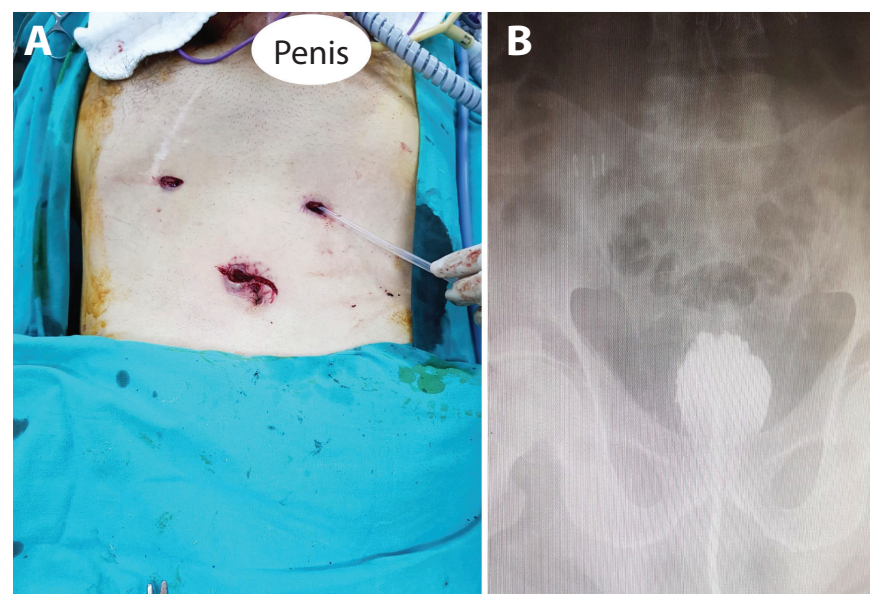

Şekil 2. Postoperatif gorüntüler: Operasyon sonrası (a). Postoperatif 1. hafta sistografi ile sonda alınmadan öncesi (b).

\section{Istatistiksel metot}

Çalışmaya dahil edilen nümerik değişkenlerin normal dağllıma uygunluğu Shapiro Wilk Testi ile sınandı. Sürekli değişkenler ortalama ve standart sapma veya medyan ve kartiller arası fark, kategorik değişkenler frekans ve yüzde değerleri kullanılarak betimlendi. Normal dağılıma sahip iki bağımsız ortalama Student t Testi ile karşılaştırıldı, normal dağılıma sahip olmayan iki bağımsız ortalamanın karşılaştırılmasında Mann Whitney U Testi kullanıldı. İki bağımsız medyan Mann Whitney U Testi ile karşılaştırıldı. İki bağımsız kategorik değişken arasındaki ilişki Ki-kare Testi ile araştırıldı. Çalışma \%95 güven düzeyinde gerçekleştirildi ( $\mathrm{p}<0,05$ istatistiksel anlamlı farklılık kabul edildi).

\section{BULGULAR}

Toplamda 92 hasta (69 hasta geleneksel eLRP, 23 hasta 3-trokar eLRP) çalışmaya alındı. Ortalama hasta yaşı $63,4 \pm 6,10$ yıl, tanıdaki ortalama PSA değeri $10,7 \pm 8,55$ ng/dL olarak bulundu. Hastaların ikisi $(\% 2,2)$ cT1b, 33’ü $(\% 35,9)$ cT1 c, 31’i $(\% 33,7)$ cT2a, 15’i $(\% 16,3)$ cT2b, 11'i $(\% 11,9)$ cT2 c klinik evredeydi. Preoperatif Gleason skoru $7(\% 7,6)$ hastada beş, $54(\% 58,7)$ hastada altı, 31 hastada $(\% 33,8) 7-9$ olarak bulunmuştur. Postoperatif patolojik evre, $14(\% 15,2)$ hasta pT2a, 8 $(\% 8,7)$ hasta pT2b, $37(\% 40,2)$ hasta pT2 c, $26(\% 28,3)$ hasta pT3a, $7(\% 7,6)$ hasta pT3b evresindeydi. Otuz bir $(\% 33,6)$ hastada sinir korumasız cerrahi uygulanırken, $61(\% 66,4)$ hastada sinir koruma uygulandı. Sinir koruyucu cerrahi uygulanan hastalardan 21 'inde $(\% 34,4)$ çift tarafl, 40 'inda $(\% 65,6)$ tek taraflı sinir koruma uyguland. On beş $(\% 16,3)$ hastada cerrahi sınır pozitifliği saptand. Operasyon süresi 3-port eLRP uygulanan grupta konvansiyonel gruba göre istatistiksel olarak anlamlı şekilde daha kısaydı $(\mathrm{p}=0,001)$. Preoperatif dönemde tümü potent olan hastalardan 46 's1 $(\% 50)$ postoperatif 6 . ayda potent iken 46'sinda (\%50) erektil disfonksiyon mevcuttu. Postoperatif ortalama IIEF-5 skoru, 5-port eLRP grubunda 18,55 $\pm 5,98,3$-port eLRP grubunda 18,26 $\pm 5,78$ idi. Her iki grubun cerrahi, onkolojik ve erken dönem fonksiyonel sonuçları arasında anlamlı fark saptanmadı (Tablo 1). 
Tablo 1. Her iki grubun demografik, cerrahi, onkolojik ve fonksiyonel sonuçları

\begin{tabular}{|c|c|c|c|}
\hline & $\begin{array}{l}5 \text { Port } \\
(n=69)\end{array}$ & $\begin{array}{l}3 \text { Port } \\
(n=23)\end{array}$ & $p$ \\
\hline Yaş (Ortalama \pm SS), yıl & $63,1 \pm 6,02$ & $64,0 \pm 6,41$ & 0,443 \\
\hline Operasyon Süresi (Medyan, KAF), dk & $155(70)$ & $120(34)$ & $0,001 *$ \\
\hline Preop PSA (Ortalama \pm SS), ng/dl & $10,4 \pm 8,31$ & $11,7 \pm 9,34$ & 0,525 \\
\hline Postop PSA (Ortalama \pm SS), ng/dl & $0,46 \pm 3,61$ & $0,04 \pm 0,08$ & 0,444 \\
\hline \multicolumn{4}{|l|}{ Preop Gleason Skor (n, \%) } \\
\hline 5 & $2(2,9)$ & $5(21,7)$ & \multirow{5}{*}{0,099} \\
\hline 6 & $41(59,4)$ & $13(56,5)$ & \\
\hline 7 & $21(30,4)$ & $5(21,7)$ & \\
\hline 8 & $3(4,3)$ & $0(0)$ & \\
\hline 9 & $2(2,9)$ & $0(0)$ & \\
\hline \multicolumn{4}{|l|}{ Postop Gleason Skor (n, \%) } \\
\hline 5 & $0(0)$ & $3(13)$ & \multirow{5}{*}{0,082} \\
\hline 6 & $43(62,3)$ & $10(43,5)$ & \\
\hline 7 & $18(26,1)$ & $8(34,8)$ & \\
\hline 8 & $3(4,3)$ & $2(8,7)$ & \\
\hline 9 & $5(7,2)$ & $0(0)$ & \\
\hline \multicolumn{4}{|l|}{ Klinik Evre (n, \%) } \\
\hline $1 b$ & $1(1,4)$ & $1(4,3)$ & \multirow{5}{*}{0,370} \\
\hline $1 \mathrm{c}$ & $24(34,8)$ & $9(39,1)$ & \\
\hline $2 a$ & $23(33,3)$ & $8(34,8)$ & \\
\hline $2 b$ & $14(20,3)$ & $1(4,3)$ & \\
\hline $2 c$ & $7(10,1)$ & $4(17,4)$ & \\
\hline \multicolumn{4}{|l|}{ Patolojik Evre (n, \%) } \\
\hline $2 a$ & $9(13)$ & $5(21,7)$ & \multirow{5}{*}{0,709} \\
\hline $2 b$ & $5(7,2)$ & $3(13)$ & \\
\hline $2 c$ & $29(42)$ & $8(34,8)$ & \\
\hline $3 a$ & $20(29)$ & $6(26,1)$ & \\
\hline $3 b$ & $6(8,7)$ & $1(4,3)$ & \\
\hline \multicolumn{4}{|l|}{ Cerrahi Sınır (n, \%) } \\
\hline Negatif & $56(81,2)$ & $21(91,3)$ & \multirow{2}{*}{0,341} \\
\hline Pozitif & $13(18,8)$ & $2(8,7)$ & \\
\hline \multicolumn{4}{|l|}{ Sinir Koruyucu (n, \%) } \\
\hline Korunmadı & $22(31,9)$ & $9(39,2)$ & \multirow{3}{*}{0,2} \\
\hline Tek taraflı & $32(46,4)$ & $8(34,8)$ & \\
\hline Çift Taraflı & $15(21,7)$ & $6(26)$ & \\
\hline \multicolumn{4}{|l|}{ Postoperatif potens durumu ( $\mathrm{n}, \%)$} \\
\hline IIEF-5<21 & $33(47,8)$ & $13(56,5)$ & \multirow{2}{*}{0,47} \\
\hline IIEF-5>21 & $36(52,2)$ & $10(43,5)$ & \\
\hline \multicolumn{4}{|l|}{ Kontinans durumu (n, \%) } \\
\hline İnkontinan & $61(88,4)$ & $20(87)$ & \multirow{2}{*}{$>0,999$} \\
\hline Kontinan & $8(11,6)$ & $3(13)$ & \\
\hline
\end{tabular}

SS, standart sapma; PSA, prostat spesifik antijen; IIEF-5, uluslararası erektil fonksiyon indeksi-5.

* İstatistiki anlamlı P değeri. 


\section{TARTIȘMA}

Kontinans ve potensi içeren fonksiyonel sonuçlar sinir koruyucu RP' nin ortaya çıkışından bu yana cerrahi kaliteyi belirleme aracı olmuştur. Ameliyat öncesi potent olan hastaların \%24-82'sinde postoperatif erektil fonksiyonlarda bozulma olduğu bildirilmektedir. ${ }^{[13,14]}$ CaPSURE çalışması RP'den bir yıl sonra hastaların sadece \%20'sinin preoperatif başlangıç erektil düzeylerine döndüğünü ortaya koymuştur. ${ }^{[15]}$ Başka bir çalışmada cerrahi öncesi potent olan 314 hasta RP ile tedavi edilmiş ve cerrahi sonrası potensin geri kazanılmasında hasta yaşı, preoperatif potens statusu ve nörovasküler bandl korunma oranı anlamlı derecede önemli olduğu tespit edilmiştir. Cerrahi sonrası 3. yılda 60 yaşından genç cerrahi öncesi tam ereksiyonu olan ve bilateral nörovasküler bandl korunan hastaların \%76'sında ilişkiyi sağlayacak kadar ereksiyonun kazanılmasının beklenebileceği bildirilmiştir. 60-65 yaş arasında bu oran \%56 ve 65 yaş üzerinde \%47 olarak bulunmuştur. ${ }^{[16]}$

Sinir koruyucu RP uygulanan hastaların, sinir koruyucu olmayanlara göre, cinsel fonksiyonlarını yeniden kazanma şansı daha yüksektir. ${ }^{[17]}$ Haffner ve ark. bilateral sinir koruyucu RP (SKRP) uygulanan erkeklerin tek taraflı ya da SKRP olmayan erkeklere göre cinsel fonksiyonların daha fazla korunduğu ve başlangıç cinsel işlevine dönme olasılıklarının daha yüksek olduğunu bildirmişlerdir. ${ }^{[18]}$ Rabbani ve ark. her iki nörovasküler demetin korunması ile $\% 55$ potens sağlanırken, birinde ya da ikisinde hasar durumunda \%41, tek taraflı rezeksiyon durumunda ise $\% 21$ potensin geri kazanımını bildirmiştir. ${ }^{[16]}$ Bununla birlikte bir çalışmada bilateral SKRP yapılan hastalarda yaş arttıkça erektil fonksiyonları devam ettirilebilme ihtimalinin azaldığı bildirilmiştir. ${ }^{[19]}$

Erektil fonksiyonların korunmasında ameliyat yöntemi de etkilidir. Minimum 1 yıllık takip sonrasında ED iyileşme oranları açık RP sonrası \%31 ile \%86 arasında ${ }^{[20]}$, LRP sonrası \%42 ile \%76 arasında olduğu gösterilmiştir. ${ }^{[21]}$ Potens oranlarının değerlendirildiği bir metaanalizde RYRP sonrası 1. yılda \%54-90, 2. yılda \%63-94 oranında potensin sağlandığı bildirilmiştir. ${ }^{[2]}$ Aynı metaanalizde RYRP operasyonunun ED riskini açık RP'ye göre \%23,6 oranında azalttığ ancak LRP’ye göre anlamlı bir üstünlüğünün olmadığı gösterilmiştir. Moran ve ark.'nın yayınladığı bir metaanalizde RYRP, erektil fonksiyonların korunmasında açık RP'ye göre daha iyi bulunurken, LRP ile arasında fark olmadığı saptanmıştır. ${ }^{[23]}$ Buna karşın açık, laparaskopik ve robot yardımlı cerrahinin karşılaştırıldığı bir derlemede RYRP'nin açık ve laparaskopik yönteme göre erektil fonksiyonların korunmasında daha üstün olduğu bildirilmiştir. ${ }^{[24]}$

Robot yardımlı RP'nin onkolojik ve fonksiyonel sonuçlar bakımından diğer yöntemlere üstünlüğ̈̈ hala tartışmalı olmakla birlikte yüksek maliyeti ve ulaşılabilirliğinin daha az olması ciddi bir dezavantaj olarak görünmektedir. ${ }^{[25]}$ Robot yardımlı RP‘e göre daha düşük maliyetli olması ve açık RP'ye göre düşük erken ve geç komplikasyon oranları, hastanın çalışma ve sosyal yaşantısına erken dönmesi LRP'yi minimal invaziv yaklaşım olarak PCa tedavisinde yaygın şekilde kullanılır hale getirmiştir. ${ }^{[26]}$ LRP'de cerrahi deneyimin artması ve cerrahi aletlerdeki endüstriyel yenilikler neticesinde daha az invaziv olan ve güvenli laparoskopik cerrahi için gerekli port sayısını azaltan LESS (Laparo-Endoscopic Single Site) Radikal Prostatektomi (LESS-RP) uygulanmaya başlanmıştır. ${ }^{[27,28]}$

Konvansiyonel LRP için 5-6 port ihtiyacı varken LESS$\mathrm{RP}$ için tek port çoklu giriş sistemine ihtiyaç vardır. Ancak LESS-RP'de laparoskop ve aletlerin kısıtlı alan içinde hareketinin zorluğu neticesinde alet çarpışması, konvansiyonel laparoskopik aletlere kıyasla bükülebilir aletlerin traksiyon gücünün daha zayıf olması ve port giriş yeri ile simfizis pubis arasındaki mesafenin uzunluğundan dolayı üretrovezikal anastomozun zorlu olması nedeniyle pek çok cerrah ilave porta ihtiyaç duymuş veya konvansiyonel laparoskopiye geçmek zorunda kalmıştır. ${ }^{[29,30]}$

Tek port LRP'nin sahip olduğu dezavantajlar konvansiyonel LRP'de port sayısını azaltmayı gündeme getirmiştir. Ancak azaltılmış port sayısı ile ilgili literatür bilgisi sınırlı olup, bu çalışmalarda RP'nin cerrahi, onkolojik ve kozmetik sonuçları değerlendirilmiştir. Barbosa Hdo N Jr ve ark. 4-port ekstraperitoneal LRP'nin prostat kanserinin tedavisinde düşük morbiditeye sahip, güvenli ve etkili bir cerrahi teknik olduğunu bildirmiştir. ${ }^{[11]}$ Akita ve ark. 2-port LRP ile konvansiyonel 5-port LRP'yi karşılaştırmış ve kozmetik avantajın yanı sıra postoperatif ağrıda anlamlı azalma ortaya koymuştur. ${ }^{[10]}$ Literatürden farklı olarak konvansiyonel 5-port LRP ile 3 port LRP'nin erken postoperatif erektil fonksiyonlar üzerine etkisini karşılaştırdığımız çalışmamızda iki grup arasında anlamlı fark saptanmadı. Cerrahi ve onkolojik sonuçlar açısından da her iki grup arasında fark olmaması kozmetik açıdan avantaja sahip 3-port LRP'yi seçenek olarak ön plana çıkarabilir.

Çalışmanın retrospektif dizaynı ve buna bağlı önemli bir ED nedeni olan psikolojik faktörlerin depresyon ya da anksiyete düzeylerinin ölçüldüğü skalalar kullanılarak değerlendirilememesi, uzun dönem sonuçların olmaması ve sınırlı hasta sayısı çalışmanın kısıtlılıkları olarak gösterilebilir.

\section{SONUÇ}

Konvansiyonel 5-port LRP ile 3-port LRP benzer onkolojik, cerrahi ve erken dönem fonksiyonel sonuçlara sahiptir. Kozmetik açıdan avantajlara sahip 3-port LRP erektil fonksiyonların korunduğu daha minimal invaziv yaklaşım olarak güvenle tercih edilebilir. 
Hakem Değerlendirmesi

Dış bağımsız

Çıkar Çatışması

Yazarlar çıkar ilişkisi olmadığını beyan etmişlerdir.

\section{Finansal Destek}

Herhangi bir mali destek alınmamıştır.

\section{Peer-review}

Externally peer-reviewed

Conflict of Interest

No conflict of interest was declared by the authors.

Financial Disclosure

No financial disclosure was received.

\section{KAYNAKLAR}

1. Heidenreich A, Bastian PJ, Bellmunt J, Bolla M, Joniau S, van der Kwast T, et al. EAU guidelines on prostate cancer. Part 1: screening, diagnosis, and local treatment with curative intent-update. Eur Urol 2013;65:124-37. [CrossRef]

2. Bianco FJ Jr, Scardino PT, Eastham JA. Radical prostatectomy: long-term cancer control and recovery of sexual and urinary function ("trifecta"). Urology 2005;66:83-94. [CrossRef]

3. Eggleston JC, Walsh PC. Radical prostatectomy with preservation of sexual function: pathological findings in the first 100 cases. J Urol 1985;134:1146-8. [CrossRef]

4. Schuessler WW, Schulam PG, Clayman RV, Vancaille TH. Laparoscopic radical prostatectomy: initial case report. J Urol 1992;147:246-7.

5. Schuessler WW, Schulam PG, Clayman RV, Kavoussi LR. Laparoscopic radical prostatectomy: initial short-term experience. Urology 1997;50:854-7. [CrossRef]

6. Guillonneau B, el-Fettouh H, Baumert H, Cathelineau X, Doublet JD, Fromont G, Vallancien G. Laparoscopic radical prostatectomy: Oncological evaluation after 1000 cases at Montsouris Institute. J Urol 2003;169:1261-6. [CrossRef]

7. Tienza A, Akin Y, Rassweiler J, Gözen AS. A match-pair analysis of continence in intermediate and high-risk prostate cancer patients after robot-assisted radical prostatectomy: the role of urine loss ratio and predictive analysis. Prostate Int 2018;6:94-8. [CrossRef]

8. Gözen AS, Tokas T, Akin Y, Klein J, Rassweiler J. Impact of barbed suture in controlling the dorsal vein complex during laparoscopic radical prostatectomy. Minim Invasive Ther Allied Technol 2015;24:108-13. [CrossRef]

9. Tracy CR, Raman JD, Cadeddu JA, Rane A. Laparoendoscopic single-site surgery in urology: where have we been and where are we heading? Nat Clin Pract Urol 2008;5:561-8. [CrossRef]

10. Akita H, Nakane A, Ando R, Yamada K, Kobayashi T, Okamura T, Kohri K.. Reduced port surgery for prostate cancer is feasible: Comparative study of 2-port laparoendoscopic and conventional 5-port laparoscopic radical prostatectomy. Asian Pac J Cancer Prev 2013;14:6311-4. [CrossRef]

11. Barbosa HN Jr, Siqueira TM Jr, Barreto F, Menezes LG, Luna MJC, Calado AA. 4-Ports endoscopic extraperitoneal radical prostatectomy: preliminary and learning curve results. Int Braz J Urol 2016;42:438-48. [CrossRef]

12. Rassweiler J, Sentker L, Seemann O, Hatzinger M, Stock C, Frede T. Heilbronn laparoscopic radical prostatectomy. Technique and results after 100 cases. Eur Urol 2001;40:54-64. [CrossRef]

13. Fulmer BR, Bissonette EA, Petroni GR, Theodorescu D. Prospective assessment of voiding and sexual function after treatment for localized prostate carcinoma: Comparison of radical prostatectomy to hormonobrachytherapy with and without external beam radiotherapy. Cancer 2001;91:2046-55. [CrossRef]
14. Potosky AL, Davis WW, Hoffman RM, Stanford JL, Stephenson RA, Penson DF, Harlan LC. Five-year outcomes after prostatectomy or radiotherapy for prostate cancer: The prostate cancer outcomes study. J Natl Cancer Inst 2004;96:1358-67. [CrossRef]

15. Hu JC, Elkin EP, Pasta DJ, Lubeck DP, Kattan MW, Carroll PR, Litwin MS. Predicting quality of life after radical prostatectomy: results from CaPSURE. J Urol 2004;171:703-8. [CrossRef]

16. Rabbani F, Stapleton AM, Kattan MW, Wheeler TM, Scardino PT. Factors predicting recovery of erections after radical prostatectomy. J Urol 2000;164:1929-34. [CrossRef]

17. Montorsi F, Briganti A, Salonia A, Rigatti P, Burnett AL. Current and future strategies for preventing and managing erectile dysfunction following radical prostatectomy. Eur Urol 2004;45:123-33. [CrossRef]

18. Haffner MC, Landis PK, Saigal CS, Carter HB, Freedland SJ. Health-related quality-of-life outcomes after anatomic retropubic radical prostatectomy in the phosphodiesterase type 5 ERA: impact of neurovascular bundle preservation. Urology 2005;66:371-6. [CrossRef]

19. Penson DF, McLerran D, Feng Z, Li L, Albertsen PC, Gilliland FD, et al. 5-year urinary and sexual outcomes after radical prostatectomy: results from the prostate cancer outcomes study. J Urol 2005;173:1701-5. [CrossRef]

20. Dubbelman YD, Dohle GR, Schröder FH. Sexual function before and after radical retropubic prostatectomy: a systematic review of prognostic indicators for a successful outcome. Eur Urol 2006;50:711-20. [CrossRef]

21. Ficarra V, Novara G, Artibani W, Cestari A, Galfano A, Graefen $\mathrm{M}$, et al. Retropubic, laparoscopic, and robot-assisted radical prostatectomy: a systematic review and cumulative analysis of comparative studies. Eur Urol 2009;55:1037-63. [CrossRef]

22. Ficarra V, Novara G, Ahlering TE, Costello A, Eastham JA, Graefen $\mathrm{M}$, et al. Systematic review and meta-analysis of studies reporting potency rates after robot-assisted radical prostatectomy. Eur Urol 2012;62:418-30. [CrossRef]

23. Moran PS, O’Neill M, Teljeur C, Flattery M, Murphy LA, Smyth G, Ryan M. Robot-assisted radical prostatectomy compared with open and laparoscopic approaches: a systematic review and metaanalysis. Int J Urol 2013;20:312-21. [CrossRef]

24. Basiri A, de la Rosette JJ, Tabatabaei S, Woo HH, Laguna MP, Shemshaki H. Comparison of retropubic, laparoscopic and robotic radical prostatectomy: who is the winner? World J Urol 2018;36:609-21. [CrossRef]

25. Bolenz C, Freedland SJ, Hollenbeck BK, Lotan Y, Lowrance WT, Nelson JB, Hu JC. Costs of radical prostatectomy for prostate cancer: a systematic review. Eur Urol 2014;65:316-24. [CrossRef]

26. Salomon L, Anastasiadis AG, Katz R, De La Taille A, Saint F, Vordos D, et al. Urinary Continence and erectile function: A prospective evaluation of functional results after radical laparoscopic prostatectomy. Eur Urol 2002;42:338-43. [CrossRef]

27. Kaouk JH, Goel RK, Haber GP, Crouzet S, Desai MM, Gill IS. Single-Port Laparoscopic Radical Prostatectomy. Urology 2008;72:1190-3. [CrossRef]

28. Humphreys MR, Castle EP, Andrews PE. Natural orifice translumenal endoscopic radical prostatectomy (notes RP): the evolution of the technique. Arch Esp Urol 2012;65:407-14.

29. Lee JY, Ha US, Lee SW. Initial Experience of Laparoendoscopic SingleSite Radical Prostatectomy Requiring Well-Equipped Appliances and a Skilled Technique. Case Rep Oncol 2010;3:445-50. [CrossRef]

30. Gao Y, Xu DF, Liu YS, Cui XG, Che JP, Yao YC, Yin L. Single plus one port laparoscopic radical prostatectomy: a report of 8 cases in one center. Chin Med J (Engl) 2011;124:1580-2. 